\title{
Seeking 'Strategy' in Business Intelligence Literature: Theorizing BI as part of strategy research
} Yassine Talaoui, Marko Kohtamäki, and Risto Rajala

\author{
/ Business intelligence is not just about turning data into information, \\ rather organizations need that data to impact how their business operates \\ and responds to the changing marketplace. "
}

Gerald Cohen

CEO and founder of Information Builders

\begin{abstract}
This paper connects the business intelligence (BI) literature with research in strategic management by plotting the existing research strands on BI: environmental scanning, competitive intelligence, executive information systems, and business intelligence, against the strategic dimensions of a) orientation (External vs. Internal), b) focus (Content vs. Process), and c) practice realms. The article accordingly offers a new re-conceptualization of BI as a strategic artifact across four strategic clusters: BI as a system, BI as a planned process, BI as a product, and BI as a decisional paradigm. This conceptual article contributes to the literature by integrating disparate views on BI and placing them within the content, process, and practice streams of strategy research.
\end{abstract}

\section{Introduction}

In today's digitized world, executives need constant access to improved real-time knowledge regarding internal layers of their organizations, along with happenings in the external business environment (Howson, 2014). They, nevertheless, face challenges in making sense of data, and assimilating and using the resulting intelligence for strategic decision-making. This conundrum is due to a fragmented business intelligence (BI) research landscape (Talaoui \& Kohtamäki, 2020) that has generated a proliferation of BI conceptualizations, which in turn has begotten overlapping views of $\mathrm{BI}$ at the operational and strategic levels. The proliferation of diverse concepts nurtures discrepancies between the intelligence executives need and what they receive. To date, BI research still desperately overlooks the strategic element of BI artifacts that are capable of providing measurable, and actionable information that bolsters executives' strategic decision making. This state of affairs calls for conceptual development that integrates the disparate views on BI (Hart, 1998) and connects them in a more coherent way with strategy research.

Against this backdrop, we inductively derive four views of BI from 120 articles spanning 35 years of research: a product view (Watson et al., 1991; Volonino et al., 1995), a process view (Calof \& Wright, 2008; Dishman \& Calof, 2008; Wright et al., 2009), a system view (Kohavi et al., 2002; Chung et al., 2005; Chaudhuri et al., 2011), and a view of BI as a decisional paradigm (Cheng et al., 2009; Holsapple et al., 2014). We then plot the four BI views against macro dimensions of strategy research: a) orientation (External vs. Internal), and b) focus (Content vs. Process). In addition, we also connect BI with strategy as practice research by juxtaposing each of the BI views against c) the practice realms of strategy work (institutional, organizational, and episodic). Overall, this paper provides an overarching conceptual view of BI and connects it with both macro and micro levels of strategy research. 


\section{Seeking 'Strategy' in Business Intelligence Literature: Theorizing BI as part of strategy research Yassine Talaoui, Marko Kohtamäki, and Risto Rajala}

\section{Uncovering BI Views}

This paper adopts a systematic methodology to distill peer reviewed articles published in the top-tier journals (ABS4/ABS3) from 1985 until 2020, thus including early landmark works of environmental scanning and business intelligence, such as Sawy (1985), Lenz and Engledow (1986b), Lenz and Engledow (1986a), and Ghoshal and Kim (1986). For this purpose, four databases were selected for the search: ABI/Inform, EBSCO academic search elite, EBSCO business premier, and Emerald journals. We used Boolean operators ("AND" and "OR"), as well as asterisk wildcards to concatenate 35 keywords and generate query strings. The presence of at least one keyword in the title, keywords, or abstracts, determined the preliminary selection of the article:

"Action* Intelligence" OR "Account* Intelligence" OR "Business Intelligence" OR "Business Analy*i*" OR "Competit* Intelligence" OR "Compet* Analy*i*" OR "Commerc* Intelligence" OR "Customer Intelligence" OR "EIS" OR "Environment* Scann*" OR "Environment* Analy*i*" OR "Financ* Intelligence" OR "Knowledge Intelligence" OR "Market* intelligence" OR "Market* Research" OR "Market* Analy*i*" OR "Network Intelligence" OR "Open Source Intelligence" OR "Operational intelligence" OR "Organizational intelligence" OR "Product* Intelligence" OR "peripheral vision" OR "Rational Intelligence" OR "Strateg* intelligence" OR "Strateg* competitiveness" OR "Srateg* Analy*i*" OR "strategic alliance intelligence" OR "Strateg* technolog* foresight" OR "Sales intelligence" OR "Service intelligence" OR "Executive information System*" OR "Industr* intelligence" OR "Indust* research" OR "Indust*Analy*i*" OR "Tactic* intelligence".

After scanning the titles, eliminating duplicates, and reviewing the abstracts, only 120 articles conceptualized the BI artifact, and therefore made the final sample. As Figure 1 illustrates, we followed Nag, Corley, and Gioia (2007) to analyze the articles for key findings and inductively distill third order categories and second order themes, as well as to derive four aggregate views of BI: BI as a product (26 Articles), BI as a planned process (36 Articles), BI as a system (34 articles), and BI as a decisional paradigm (24 articles).

From this volume of publications, one can say we know a considerable amount about BI and its conceptual underpinnings, although explanatory studies that depict concrete frameworks of analysis and ways to coherently measure intelligence value have yet to come. The choice to uphold multiple disparate definitions at the same time led to a fragmented literature, not to mention discontinuity between concept descriptions and their defined strategic roles. Missing strategic thinking appears to be common across the four research streams related to BI.

It thus seems now is a suitable time to connect $\mathrm{BI}$ to the strategy literature within which the need for BI is manifested at different schools of strategy work. These schools include content (Porter, 1991; Rumelt et al., 1994), process (Chakravarthy \& Doz, 1992; Van de Ven, 1992), and practice (Johnson et al., 2003; Whittington, 2007). Closer scrutiny of the literature has now uncovered shades of strategy content and process schools, and strategy practice stream. Juxtaposing the four BI views with three strategic variables: environment layer, strategic focus of analysis, and realms of strategy practice, enabled us to connect BI views to the outside-in and inside-out perspectives of strategy as illustrated in Figure 2. Likewise, we were able to place the four views within the realms of strategy as practice research, indicated in Figure 3.

In the following two sections, we aim to bring together the four BI views and the three schools of strategy research in an attempt to delineate how each BI view is implemented on the strategy levels of analysis.

\section{Bringing BI Views to the Strategy Content and Process Realms}

\section{BI as a product}

Together environmental scanning and competitive intelligence (CI) represent the main constituents of BI within this dimension. They adopt an outside-in perspective that considers information collected about an external environment as the intelligence product itself. Thirty years of research has turned out vast amounts oriented towards information acquisition, which unless analyzed, remains of no avail and little value to decision makers. While some scholars have advocated information analysis, the focus and objective of such an evaluation has been largely missing (Vedder et al., 1999; Dishman \& Calof, 2008; Wright et al., 2009). The lines of thinking underlying BI as a product dimension, nonetheless, seems to consort with the positioning school of strategic management, which, 


\section{Seeking 'Strategy' in Business Intelligence Literature: Theorizing BI as part of strategy research Yassine Talaoui, Marko Kohtamäki, and Risto Rajala}

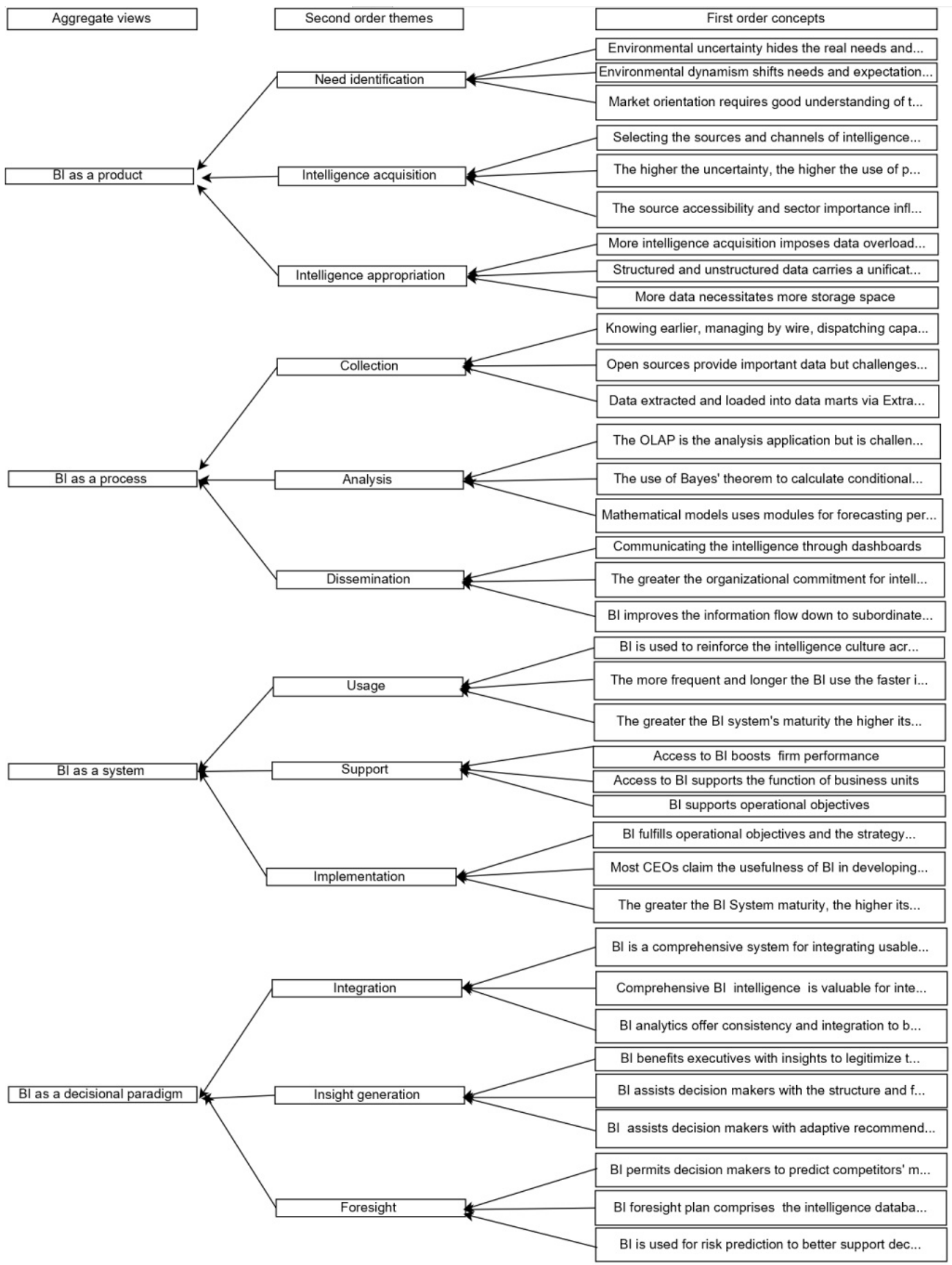

Figure 1. The $4 \mathrm{BI}$ views derived inductively out of third and second order categories from the literature. 


\section{Seeking 'Strategy' in Business Intelligence Literature: Theorizing BI as part of strategy research Yassine Talaoui, Marko Kohtamäki, and Risto Rajala}

thanks to its excessive external focus, posits that a firm's capacity to create and sustain competitive advantage hinges on how well it positions itself within its industry (Hoskinsson et al., 1999). Put differently, competitors' positioning along existing structural conditions of the industry have been claimed as primary determinants of company performance (Mintzberg et al., 1998).

In this vein, Porter's 1980 five forces analytical framework has allowed firms to assess their performance through scrutiny of their positioning within respective industries, as well as estimating their bargaining power vis-à-vis existing or potential rivalries (Rumelt et al., 1994). The five forces appraisal, while mostly quantitative, has been deemed essential for generic strategy formulation, in drawing a clear picture of industry structure (Porter, 1980; Mintzberg et al., 1998). Strangely, heuristics found within the positioning school are constantly mentioned by companies and appraised by scholars falling within this dimension, although no research so far has attempted to link BI constructs to the positioning paradigm of strategic management.

Furthermore, through primary human or open sources, environmental scanning and CI academics try to detect trends or events that might occur in the external environment that may jeopardize organizations' CI $(\mathrm{Xu}$ et al., 2011; Zheng et al., 2012). The rationale here stems from the new dynamics of business environment after the internet bubble of the late 1990s. During the last two decades, a new reality has emerged: competitive advantage is transitory and ephemeral. This fact broke with the positioning school's premise in favour of taking a competitive dynamics approach, wherein firm performance hinges upon effective action/reaction responses (Chen et al., 2012). Once again, prescriptive environmental scanning and CI research overlap with strategic management through competitive dynamics, and consequently comprise BI as a product dimension. This dimension combines environmental scanning and CI with two outside-in content schools: the positioning school and a competitive dynamics research stream. By doing this, BI as a product cluster puts two BI constructs into corresponding strategic context and holds twofold endeavours: (1) supplementing the existing theoretical framework of industry analysis that has long been criticized for its static nature and inability to sense industry alterations (Kim \& Mauborgne, 2004), and (2) acknowledging the complementarity of both strategic management schools, by merging their underlying units of analysis, industry and products (Teece et al., 1997), as two crucial sides of the intelligence continuum.

\section{BI as a planned process}

This dimension draws from a myriad of studies adopting the CI process or cycle as a reference to evaluate firms' intelligence practices (Wright \& Calof, 2006; Dishman \& Calof, 2008; Fleisher, 2008). Such a process is composed of four steps: planning, collection, analysis, and dissemination. Put differently, the entire intelligence sequence hinges on a clear delineation of objectives and needs before subsequent stages are triggered. This CI cycle has enjoyed much interest since the late 60's, and is likely to continue its pace, particularly among the Society of Competitive Intelligence Professionals (SCIP). Although, CI practitioners were heavily focussed on the collection phase, likewise scholars advocated for an intertwined cycle that lays the building bricks of actionable intelligence.

Ostensibly, the intelligence is gauged as actionable if it limits executives' intuitions and feeds their rational decision making through a full gamut of activities. These range from an accurate assessment of data validity and quantitative analysis for underlying patterns to imparting knowledge with numerical face value. Needless to say, such a set of actions requires proper intelligence creation, while delivery stems from marketing research. This rational and prescriptive tradition shares a discernable similarity with Ansoff's (1965) planning school of strategy. In other words, both the CI process and strategy planning school draw upon a linear sequential model of development to generate intelligent solutions for wicked issues in strategy formulation (Mason \& Mitroff, 1981).

Accordingly, strategy formulation result from a formal, sequential, and rational process comprised of closely weaved phases (Huff \& Reger, 1987). At the same time, for the planning to succeed, strategies and objectives ought to be carefully explicated throughout an organization, along with establishing the need for a stable structure that behooves this iterative, if not strenuous, duty (Rialp-Criado et al., 2010). Surprisingly, the regular disparity between needed and produced intelligence has so far been misinterpreted by most scholars, who have opted to delve into the prowess of formalizing intelligence units, or favored a project-based approach for the entire intelligence process (Prescott \& Smith, 1987; Ghosal \& Westney, 1991).

This paper, therefore, suggests a similarity between the planning school and CI cycle, and places the latter within the confines of the former. Both are rooted in a rational-formal synoptic model and adopt a systematic, 


\section{Seeking 'Strategy' in Business Intelligence Literature: Theorizing BI as part of strategy research Yassine Talaoui, Marko Kohtamäki, and Risto Rajala}

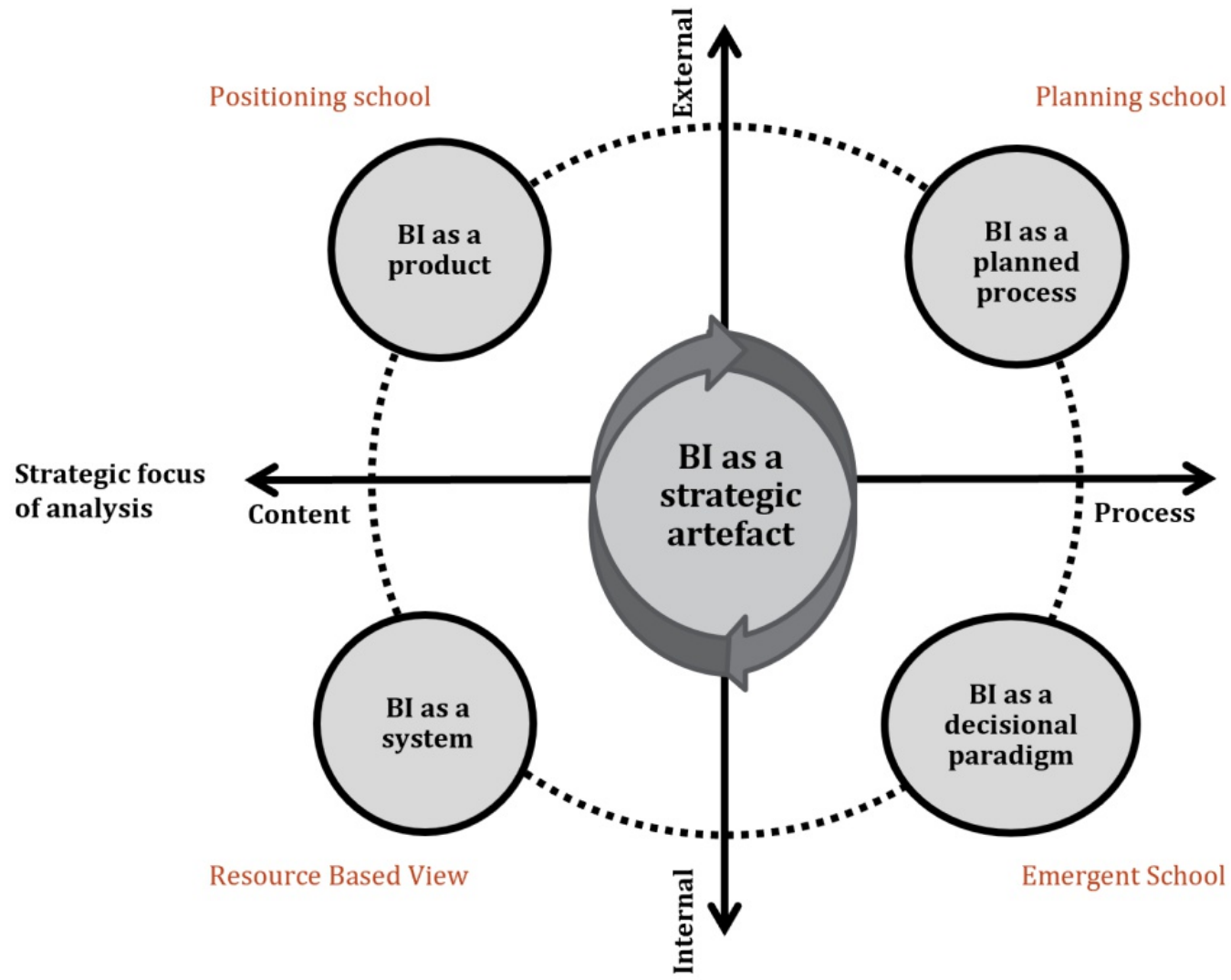

Orientation

Figure 2. BI views against the outside-in and inside-out views of strategy.

comprehensive, and exhaustive analysis approach to the environment prior to decision execution (Fredrickson \& Mitchell, 1984). Such an integration of CI cycles into the planning school is presumably considered key to synchronizing between what is needed at the top and what is offered as an intelligence outcome. Only then will rational strategy formulation supplant intuition.

\section{BI as a system}

To bridge the gap between the business user and information access, BI applications ranging from data warehousing, online analytical processing (OLAP), data mining, extract-transform-load (ETL), and user interface provide a company's executive information system with the necessary technologies to process huge volumes of unstructured data, in order to present it in a timely manner to executives. Whereas the research debate stressed WEB 2.0's information overload and the type of business user (executive vs. line manager) receiving the intelligence, studies addressing the strategic importance of such technologies are, unfortunately, nonexistent.
Ultimately, investing in state-of-the-art technologies to decipher meaning out of noisy internal and external data is necessary for companies to strive forward in today's turbulent business environment. However, if such technologies are not seen as a means to competitive advantage, then the continuous investment in updating and developing this arsenal will eventually come to an end. This implies an inside-out perspective to strategy formulation whereby focus shifts to the firm's internal capabilities as a determinant of its strategy and competitive advantage (Hoskinsson et al., 1999). In this respect, firms may earn above normal returns, by identifying and acquiring resources, for instance, BI technologies that are critical to the development of demanded products (Newbert, 2007). These resources are, nonetheless, heterogeneously distributed across competing firms and are imperfectly mobile, which in turn makes the heterogeneity persist over time (Barney, 1991). Firms owning valuable and rare resources would a priori attain a competitive advantage and enjoy improved performance in the short term (Barney, 1991). 


\section{Seeking 'Strategy' in Business Intelligence Literature: Theorizing BI as part of strategy research Yassine Talaoui, Marko Kohtamäki, and Risto Rajala}

This rationale, however, seems dubious in the context of volatile and unpredictable environments as it fails to address the influence of market dynamism and firm transformation over time (Wang \& Pervaiz, 2007), let alone the ambiguity surrounding processes whereby resources yield competitive advantage (Barney, 2001). The latter involves making better use of resources by allocating them in such a way that maximizes performance (Mahoney \& Pandian, 1992). In this respect, once a firm's valuable resources are properly leveraged, competitive advantage should hence be obtained (Peteraf, 1993).

Evidently, competitive advantage emanates from a combination of resource possession and resource exploitation, which is best captured under two theoretical approaches within the resource-based view: the VRIO framework (Barney, 1997), and the dynamic capabilities approach (Teece et al., 1997). Whereas the former stresses a firm's need to organize for full exploitation of its VRIN resources to potentially attain competitive advantage, the latter specifically defines the types of processes by which firms could reconfigure those resources (Teece et al., 1997).

As conjectured earlier, this line of thinking views BI technologies as necessary but not sufficient for a firm's competitive advantage. It ascertains that above normal rents are earned once firms possess and are capable of replicating routines, whereby resources can be coordinated and deployed. Resources themselves are thus seemingly of no real value to the firm in isolation. Instead, their latent value can only be made available to the firm via idiosyncratic dynamic capabilities (Eisenhardt \& Martin, 2000), which: (a) are built rather than bought, (2) reflect a firm's ability to integrate, build, and reconfigure internal and external competences, (3) creation and evolution are embedded in organizational processes that are shaped by firms' asset positions and development paths adopted in the past (Barreto, 2010). In addition to the resource reconfiguring capability, two other sets of capabilities should be considered: the capability to sense and shape opportunities and the capability to seize them (Teece, 2007).

Ultimately, sustainable competitive advantage does not rely solely on dynamic capabilities themselves, but also on resource configurations through BI applications that permit using dynamic capabilities "sooner, more astutely, and more fortuitously than the competition" (Eisenhardt \& Martin, 2000). In this respect, BI technologies, along with EIS form the basis for a firm's capabilities to create and sustain competitive advantage (Collis, 1994).

\section{BI as a decisional paradigm}

Although some studies have pictured BI as a decisional paradigm, their line of thinking has preached formal alignment between analytical culture, BI technologies, and the business unit (Holsapple et al., 2014). Put differently, this means supporting real time decision making through a combination of BI techniques (cube and ad hoc query analysis, statistical analysis, data mining) with a standard knowledge management process (knowledge retrieval, storage, and dissemination) to generate data, select and manipulate it (Cheng et al., 2009). The validity of such an argument depends on the kind of environment: benign vs. uncertain. While in the former, BI may be utilized for long-term strategic planning, in the latter, BI facilitates adaptation and strategic learning.

This seemingly dimension arises as the missing part of our puzzle. For BI to succeed as a decisional paradigm, an inside-out orientation is necessary, but not sufficient, as it should reckon business interactions with the external environment that imply unintended outcomes of the strategic process (Cyert \& March, 1963). Strategy then becomes the result of adaptive opportunistic behavior rather than a plan, for the process is fragmentary and unpredictable, in which intended strategies frequently lead to unintended results (Mintzberg \& Waters, 1985). In this regard, both strategy formation and implementation arise as inseparable and indistinguishable processes (Mintzberg et al., 1998). As a corollary, trial and error, continuous learning, and a two-way flow of information emerge as key determinants for resilient, astute real time decision making (Quinn, 1980; Mintzberg, 1987).

Meanwhile, learning is not exclusive to managers who are limited cognitively due to bounded rationality, but permeates the entire organization through a new culture and behaviour that favours retrospective thinking (Quinn, 1980; Mintzberg, 1987), and exudes considerable recognition of the contextual role in strategic thinking (Ezzamel \& Willmott, 2004). Therefore, unlike the aforementioned dimensions, this article presents the fourth dimension of the literature in line with the processual school of strategy, wherein decision making process is unpredicted, and associated with a continuous learning process (Whittington \& Cailluet, 2008). This double-loop, often triple-loop, type of learning depends on BI to provide the necessary inputs 


\section{Seeking 'Strategy' in Business Intelligence Literature: Theorizing BI as part of strategy research Yassine Talaoui, Marko Kohtamäki, and Risto Rajala}

for incessant modifications to better cope with contextual changes before strategy can be formed in a collected and descriptive manner (Mintzberg \& Waters, 1985; Balogun \& Gleadle, 2005).

\section{Placing BI within the Three Realms of Strategy as Practice}

\section{$B I$ as a system within the strategy realm}

Research rooted in information management and oriented toward technologies that drive intelligence currently offer potential within the operational realm, not to mention carrying a would-be role for accompanying the organizational realm. Research so far has been concerned a great deal with developing the ultimate BI software capable of generating reliable intelligence. This in turn has yielded hands-on technologies that are responsible for converting structured as well as mostly unstructured data into a homogenous piece of knowledge that reflects the actual conduct of business units. This episodic focus is achieved through an application dubbed extracttransform-load (ETL) because it alleviates heterogeneity and load extracted data into a data warehouse. The latter result contributes much to the organizational realm, thanks to a relational database management system (RDBMS) that enables business users to execute queries across a wide range of data.

The organizational focus is further corroborated by an online analytic processing (OLAP) server, which is tasked with deciphering patterns across data to better fathom competition and strategic change. In this regard, OLAP offers organizational actors the possibility to slice, dice, and drill down into data, and then to display it in a user friendly manner through dashboards or spreadsheets that constitute the interface for a decision support system (DSS), also known as an executive information system (EIS).

Finally, the potential role of BI technologies within the institutional realm is not as straightforward as one might think, despite the ability of data mining engines to "predict" scenarios vis-à-vis the focal firm's environment (March \& Hevner, 2007; Chaudhuri et al., 2011). Besides the difficulty of predicting accurate scenarios, the currently rudimentary routines of companies to acquire external data also impedes the capability of data mining from making sense of the institutional realm. Thus far, research has addressed the potential role of BI technologies within the three strategy realms, yet more empirical research is needed to highlight how BI as a system shapes and is influenced by each realm.

\section{BI as a product within the strategy realm}

In line with the structure-conduct-performance paradigm and influenced by "industrial organization" (IO) economics, strategic management scholars have nurtured a particular interest in the structure of a given firm's industry as crucial to formulating viable business strategies. Their outside-in perspective has been referred to as environmental scanning and shares discernable synergy with the institutional realm, as it

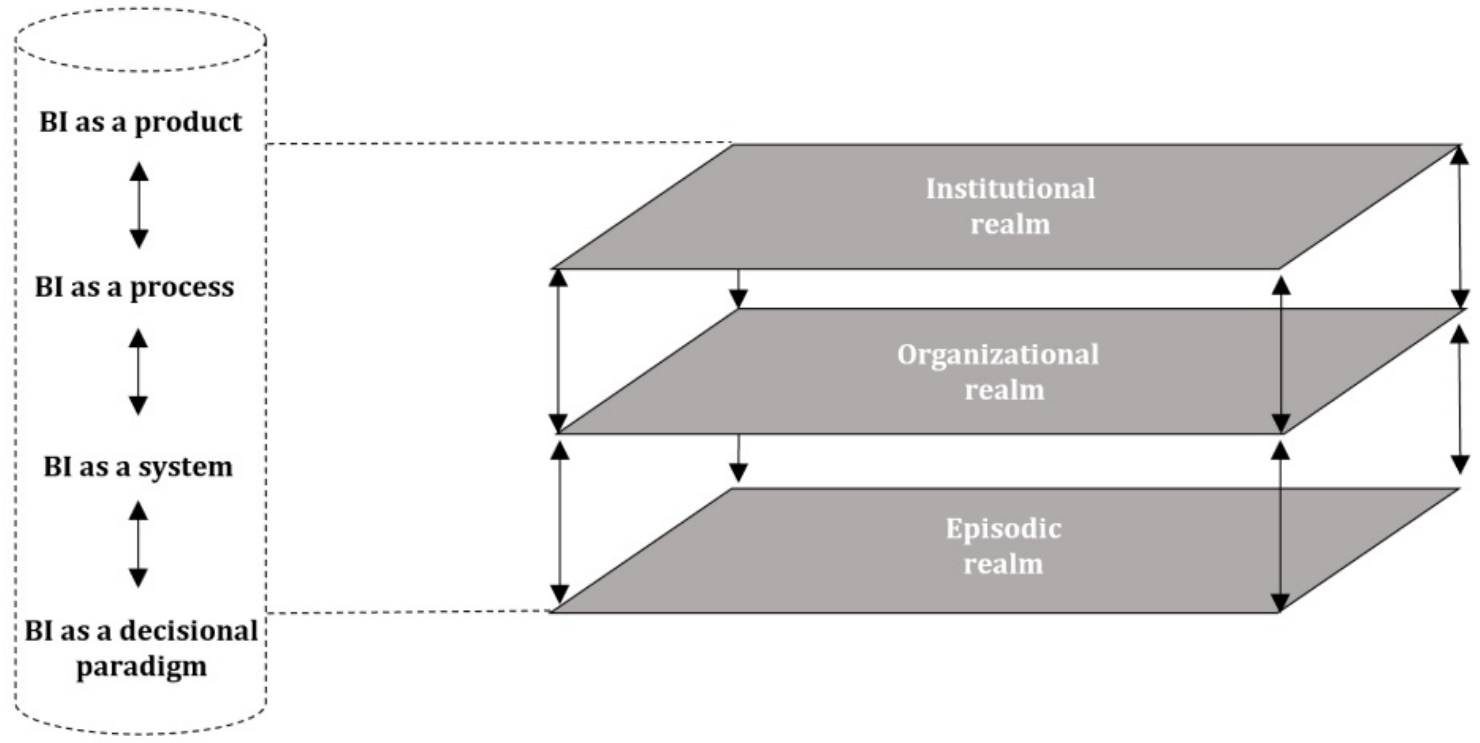

Figure 3. BI views against the three realms of strategy as practice. 


\section{Seeking 'Strategy' in Business Intelligence Literature: Theorizing BI as part of strategy research Yassine Talaoui, Marko Kohtamäki, and Risto Rajala}

strives to make sense of the task environment (which includes any area directly linked to the organization's operations, such as customers, competitors, and so forth), and the general environment (denoting all sectors remotely connected to the organization including government and economy) (Daft et al., 1988).

Nowadays, such market focused intelligence is generated through third party sources, customer reviews, and Web 2.0's overwhelming loads of information. These three modes represent major bases upon which CI is created within 21st century organizations. Whether developed internally or acquired by market researchers, mainly Nielsen, the operational efficiency concern of CI bears a striking resemblance to the organizational realm. Put differently, the acquisition techniques of $\mathrm{CI}$ through the mining of customer reviews or the inference of competitive measures (market share, competitors' share of wallet) seeks potential weaknesses or strengths of competitors' products or services in order to avoid competition and anticipate strategic change (Zheng et al., 2012).

Unfortunately, strategic management and marketing scholarship that has been preoccupied with strategic uncertainty and awed by the heuristics of Porter's positioning school, has produced much quantity aimed at the institutional realm, which however disregards the distinctive competence and capabilities of organizational actors. This in turn has engendered a challenge to trace the BI construct to the episodic realm. It has thus become evident that the extant literature has failed to notice the interplay between the three realms indicated above, which is reflected in the paramount weight given to the institutional realm, and a shocking lack of episodic level analyses engrained in many firms' resource base. Needless to say, though the many contributions of marketing scholars have benefited the organizational realm, their customer-oriented approach has accidently coincided with operational efficiency, while missing the CI entrenched in a business model's set of activities.

\section{$B I$ as a process within the strategy realm}

$\mathrm{BI}$ as a process is by far and large the construct with the most prescriptive and descriptive studies. This state of affairs, fueled by a desire to bridge the gap between business users and their BI system, has lured researchers to reduce the time cycle from data collection to imparting knowledge via casual visualization that aims at simplifying common quantitative displays of data (Kohavi et al., 2002).This communication seemingly follows a predefined process that could be traced to the episodic and organizational realms. The episodic realm permeates the acquisition of internal data that exposes the distinctive competence of a company, its activities, and actors, while the latter shifts attention to the transformation of data into consistent and coherent actionable intelligence that serves immediate operational analysis or awaits more variables to foster sense making (Chen et al., 2012).

The organizational realm holds within its confines a striking disappointment for most readers, due to the absence of any tested analysis tools that are proficient in examining data according to different scenarios of consequence for competitive dynamics. Lastly, communication and intelligence sharing throughout an organization has been called for by scholars and mangers alike, despite the clear deficiency in comprehending the institutional realm. Along with its linkage to the aforementioned dimensions, this ultimately drives the persisting conflict and divergence between intelligence needed at the top and intelligence conveyed bottom up.

\section{BI as a decisional paradigm within the strategy realm}

As mentioned earlier, BI as a decisional paradigm hinges on the continuous input of intelligence needed for making necessary amendments prior to and during the strategy formation process, which involves trial and error learning (Quinn, 1980; Mintzberg, 1987). This BI dimension in tandem with the processual school of strategy carries also a synergy in accordance with the institutional realm, thanks to giving the utmost consideration to interactions with the external environment, due to the tension it exerts upon the decision making process (Whittington \& Cailluet, 2008). On the contrary, the emphasis information management scholars have given to studying the impact of internal environments on BI as a set of core resources, has discovered a clear association between intelligence assimilation and managerial absorptive capacity (Elbashir et al., 2011).

Ostensibly, better intelligence assimilation needs to be supported by potential absorptive capacity (ACAP), which enables information acquisition and assimilation (Lane \& Lubatkin, 1998). Regrettably, unless or until such a relationship is explored to indicate a clear link between BI and either potential absorptive capacity (ACAP) or absorptive capacity (RACAP) (Zahra \& George, 2002), one cannot conjecture any role for BI in delineating the understating and motives that drive 


\section{Seeking 'Strategy' in Business Intelligence Literature: Theorizing BI as part of strategy research Yassine Talaoui, Marko Kohtamäki, and Risto Rajala}

organizational actions taking place within the episodic realm.

Notwithstanding this fact, piecing together the tactical level with BI might not be utterly wrong, as a distinct relation seems to exist between the speed and extent of such actions and BI (Leidner \& Elam, 1995; Leidner et al., 1999). This goes along with a discernable connection particularly in instances entailing prediction for mergers \& acquisitions (Lau et al., 2012), and credit denial or approval (Moro et al., 2015). In contrast with the episodic level of analysis, linking BI to the organizational realm usually holds value, due for the most part to the ease of quantitatively measuring operational efficiency related constructs. For instance, resource and price optimization based on data mining forecasts from previous patterns and competitors' pricing, which ultimately enables retaliatory or preemptive actions with respect to competition (Heinrichs \& Lim, 2003).

\section{Conclusion}

This conceptual paper aimed to integrate the BI and strategy literatures by clustering the BI body of knowledge around four BI views, which are further placed into the strategy schools: BI as a product, BI as a system, BI as planned process, and BI as a decisional paradigm. By so doing, this paper endeavoured to direct scholars' attention to the subtle strategic role of BI that has been long neglected. Thus, this paper intended to encourage a change in perspective for researchers to adopt a more comprehensive view of BI aimed at facilitating real time decision making and strategic learning (Mintzberg \& Lampel, 1999). With its focus on four BI dimensions, the paper at hand has laid the first brick in a new BI wall, where more studies are expected to probe the influence of managerial cognition of BI usage and interpretation, as a way to enhance our understanding of the BI influence on strategy making. From a capability perspective, researchers should examine the role of BI to accumulate and share tacit knowledge throughout organizations. Further studies thus appear to be needed in order to shed light on the interaction between BI and different strategy constructs. In addition, we believe that taking a strategy-as-practice approach could provide fruitful grounds to study the utilization of BI technologies in management teams and middle management. This way studies can shed light on the material forms of BI systems, along with how BI systems and social practices get entangled.

\section{References}

Ansoff, I.H. 1965. Corporate Strategy. New York: McGraw-Hill.

Balogun, J., \& Gleadle, P. 2005. Managing change across boundaries: Boundary-shaking practices. British Journal of Management, 16(4): 261-278.

Barney, J. 1991. Firm Resources and Sustained Competitive Advantage. Journal of Management, 17(1): 99-120.

Barney, J. 1997. Gaining and Sustaining Competitive Advantage. Addison-Wesley.

Barney, J. 2001. Is the Resource-Based "View" a Useful Perspective for Strategic Management Research? Yes. The Academy of Management Review, 26(1): 41-56.

Barreto, I. 2010. Dynamic Capabilities: A Review of Past Research and an Agenda for the Future. Journal of Management, 36(1): 256-280.

Calof, J.L., \& Wright, S. 2008. Competitive intelligence: A practitioner, academic and inter-disciplinary perspective. European Journal of Marketing, 42(7/8): 717-730.

Chakravarthy, B.S., \& Doz, Y. 1992. Strategy process research: Focusing on corporate self-renewal. Strategic Management Journal, 13: 5-14.

Chaudhuri, S., Dayal, U., \& Narasayya, V. 2011. An overview of business intelligence technology. Communications of the ACM, 54(8): 88.

Chen, H., Chau, M., \& Zeng, D. 2002. CI Spider: A tool for competitive intelligence on the Web. Decision Support Systems, 34(1): 1-17.

Chen, H., Chiang, R.H.L., \& Storey, V.C. 2012. Business Intelligence and analytics: From Big Data To Big Impact. MIS Quarterly, 36(4): 1165-1188.

Cheng, H., Lu, Y.-C., \& Sheu, C. 2009. An ontology-based business intelligence application in a financial knowledge management system. Expert Systems with Applications, 36(2): 3614-3622.

Chung, W., Chen, H., Nunamaker, J.F.J., \& Nunamaker Jr, J.F. 2005. A visual framework for knowledge discovery on the Web: An empirical study of business intelligence exploration. Journal of Management Information Systems, 21(4): 57-84.

Collis, D.J. 1994. Research Note: How Valuable are Organizational Capabilities? Strategic Organization, 15(1): 143-152.

Cyert, R., \& March, J. 1963. A Behavioral Theory of the Firm. Englewood Cliffs, NJ: Prentice-Hall.

Daft, R.L., Sormunen, J., \& Parks, D. 1988. Chief executive scanning, environmental characteristics, and company performance: An empirical study. Strategic Management Journal, 9(2): 123-139.

Dishman, P.L., \& Calof, J.L. 2008. Competitive intelligence: a multiphasic precedent to marketing strategy. European Journal of Marketing, 42(7/8): 766785 . 


\section{Seeking 'Strategy' in Business Intelligence Literature: Theorizing BI as part of strategy research Yassine Talaoui, Marko Kohtamäki, and Risto Rajala}

Eisenhardt, K.M., \& Martin, Jeffrey A. 2000. Dynamic capabilities: what are they? Strategic Management Journal, 21(10-11): 1105-1121.

Elbashir, M.Z., Collier, P.A., \& Sutton, S.G. 2011. The role of organizational absorptive capacity in strategic use of business intelligence to support integrated management control systems. Accounting Review, 86(1): 155-184.

Ezzamel, M., \& Willmott, H. 2004. Rethinking strategy: contemporary perspectives and debates. European Management Review, 1(1): 43-48.

Fleisher, C.S. 2008. Using open source data in developing competitive and marketing intelligence. European Journal of Marketing, 42(7/8): 852-866.

Fredrickson, J.W., \& Mitchell, T.R. 1984. Strategic Decision Processes: Comprehensiveness and Performance in an Industry with an Unstable Environment. Academy of Management Journal, 27(2): 399-423.

Ghoshal, S., \& Kim, S.K. 1986. Building effective intelligence systems for competitive advantage. Sloan Management Review, 28(1): 49-58.

Ghosal, S., \& Westney, E.D. 1991. Organizaing competitor analysis systems. Strategic Management Journal, 12(1): 17-31.

Hart, C. 1998. Doing a literature review: Releasing the social science research imagination. London: Sage.

Heinrichs, J.H., \& Lim, J.S. 2003. Integrating web-based data mining tools with business models for knowledge management. Decision Support Systems, 35(1): 103-112.

Holsapple, C., Lee-Post, A., \& Pakath, R. 2014. A unified foundation for business analytics. Decision Support Systems, 64: 130-141.

Hoskinsson, R.E., Hitt, M.A., Wan, W.P., \& Yiu, D. 1999. Theory and research in strategic management: Swings of a pendulum. Journal of Management, 25(3): 417456.

Howson, Cindy. 2014. Successful Business Intelligence: Unlock the Value of BI \& Big Data (second edition). McGraw Hill education.

Huff, A., \& Reger, R. 1987. A Review of Strategic Process Research. Journal of Management, 13(2): 211-236.

Johnson, G., Langley, A., Melin, L., \& Whittington, R. 2007. Strategy as Practice: Research Directions and Resources. Cambridge: Cambridge University Press.

Kim, W.C., \& Mauborgne, R. 2004. Blue ocean strategy. Harvard Business Review, October.

Kohavi, R., Rothleder, N.J., \& Simoudis, E. 2002. Emerging trends in business analytics. Communications of the ACM, 45(8): 45-48.

Lane, Peter J., \& Lubatkin, M. 1998. Relative absorptive capacity and interorganizational learning. Strategic Management Journal, 19: 461-477.
Lau, R.Y., Liao, S.S.Y., Wong, K. ., \& Chiu, D.K.W. 2012. Web 2.0 environmental scanning and adaptive decision support for business mergers and acquisitions. MIS Quarterly, 36(2): 1239-1268.

Leidner, D.E., Carlsson, S., Elam, J., \& Corrales, M. 1999. Mexican and Swedish Managers' Perceptions of the Impact of EIS on Organizational Intelligence, Decision Making, and Structure. Decision Sciences, 30(3): 632-658.

Leidner, D.E., \& Elam, J.J. 1995. The Impact of Executive Information Systems on Organizational Design, Intelligence, and Decision Making. Organization Science, 6(6): 645-664.

Lenz, R., \& Engledow, J. 1986a. Environmental analysis: The applicability of current theory. Strategic Management Journal, 7: 329-346.

Lenz, R., \& Engledow, J. 1986b. Environmental analysis units and strategic decision-making: A field study of selected 'leading-edge' corporations. Strategic Management Journal, 7(1): 69-89.

Mahoney, J.T., \& Pandian, R.J. 1992. The resource-based view within the conversation of strategic management. Strategic Management Journal, 13(5): 363-380.

March, S.T., \& Hevner, A.R. 2007. Integrated decision support systems: A data warehousing perspective. Decision Support Systems, 43(3): 1031-1043.

Mason, R.O., \& Mitroff, I.I. 1981. Challenging Strategic Planning Assumptions: Theory, Cases and Techniques. New York: Wiley.

Mintzberg, H. 1987. Crafting Strategy. Harvard Business Review, (July-August): 66-75.

Mintzberg, H., Ahlstrand, B., \& Lampel, J. 1998. Strategy Safari: A Guided Tour through the Wilds of Strategic Management. Free Press.

Mintzberg, H., \& Lampel, J. 1999. Reflecting on the Strategy Process. Sloan Management Review, 40(3): 21-30.

Mintzberg, H., \& Waters, J.A. 1985. Of strategies, deliberate and emergent. Strategic Management Journal, 6(3): 257272.

Moro, S., Cortez, P., \& Rita, P. 2015. Business intelligence in banking: A literature analysis from 2002 to 2013 using text mining and latent Dirichlet allocation. Expert Systems with Applications, 42(3): 1314-1324.

Nag, R., Corley, K.G., \& Gioia, D.A. 2007. The intersection of organizational identity, knowledge, and practice: Attempting strategic change via knowledge crafting. Academy of Management Journal, 50(4): 821-847.

Newbert, S.L. 2007. Empirical research on the resourcebased view of the firm: an assessment and suggestions for future research. Strategic Management Journal, 28(2): 121-146.

Peteraf, M.A. 1993. The cornerstones of competitive advantage: A resource-based view. Strategic Management Journal, 14(3): 179-191. 


\section{Seeking 'Strategy' in Business Intelligence Literature: Theorizing BI as part of strategy research Yassine Talaoui, Marko Kohtamäki, and Risto Rajala}

Porter, M.E. 1980. Competitive Strategy: Techniques for Analyzing Industries and Competitors. New York: Free press.

Porter, M.E. 1991. Towards a dynamic theory of strategy. Strategic Management Journal, 12: 95-117.

Prescott, John E., \& Smith, Daniel C. 1987. A projectbased approach to competitive analysis. Strategic Management Journal, 8(5): 411-423.

Quinn, J.B. 1980. No Title. MIT Sloan Management Review, July.

Rialp-Criado, A., Galvan-Sanchez, I., \& Suarez-Ortega, S.M. 2010. A configuration-holistic approach to bornglobal firms' strategy formation process. European Management Journal, 28(2): 108-123.

Rumelt, R., Schendel, D., \& Teece, D. 1994. Fundamental issues in strategy. Boston: Harvard Business School Press.

Sawy, O.El. 1985. Personal information systems for strategic scanning in turbulent environments: can the CEO go on-line? MIS Quarterly, 61: 53-60.

Talaoui, Y., \& Kohtamäki, M. 2020. Of BI research: a tale of two communities. Management Research Review.

Teece, D.J. 2007. Explicating dynamic capabilities: the nature and microfoundations of (sustainable) enterprise performance. Strategic Management Journal, 28(13): 1319-1350.

Teece, D.J., Pisano, G., \& Shuen, A. 1997. Dynamic capabilities and strategic management. Strategic Management Journal, 18(7): 509-533.

Van de Ven, A.H. 1992. Suggestions for studying strategy process: A research note. Strategic Management Journal, 13(5): 169-188.

Vedder, R.G., Vanecek, M.T., Guynes, S.C., \& Cappel, J.J. 1999. CEO and CIO perspectives on competitive intelligence. Communications of the ACM, 42(8): 108116.

Volonino, L., Watson, H.J., \& Robinson, S. 1995. Using EIS to respond to dynamic business conditions. Decision Support Systems, 14(2): 105-116.

Wang, Catherine L., \& Pervaiz, A.K. 2007. Dynamic capabilities: A review and research agenda. International Journal of Management Reviews, 9(1): 31-51.

Watson, H.J., Rainer, R. Kelly Jr., \& Koh, C.E. 1991. Executive information systems: a framework for development and a survey of current practices. MIS Quarterly.

Whittington, R., \& Cailluet, L. 2008. The crafts of strategy: Introduction to special issue. Long Range Planning, 41(3): 241-247.

Whittington, R. 2007. Strategy practice and strategy process: Family differences and the sociological Eye. Organization Studies, 28(10): 1575-1586.
Wright, S., \& Calof, J.L. 2006. The Quest for competitive, business and marketing intelligence: A country comparison of current practices. European Journal of Marketing, 40(5/6): 453-465.

Wright, S., Eid, E.R., \& Fleisher, Craig S. 2009 Competitive intelligence in practice: empirical evidence from the UK retail banking sector. Journal of Marketing Management, 25(9): 941-964.

$\mathrm{Xu}$, K., Liao, S.S., Li, J., \& Song, Y. 2011. Mining comparative opinions from customer reviews for Competitive Intelligence. Decision Support Systems, 50(4): 743-754.

Zahra, S.A., \& George, G. 2002. Absorptive Capacity: A Review, Reconceptualization, and Extension. The Academy of Management Review, 27(2): 185-203.

Zheng, Z.E., Fader, P., \& Padmanabhan, B. 2012. From Business Intelligence to Competitive Intelligence: Inferring Competitive Measures Using Augmented Site-Centric Data. Information Systems Research Publication, 23(3): 698-720.

\section{About the Authors}

Yassine Talaoui is a researcher at the School of Management at the University of Vaasa, where he teaches business models and strategy work. His research interests focus on strategy work, practice theory, BI analytics, materiality, and sociomateriality.

Marko Kohtamäki is a Professor of Strategy, director of the "Strategic Business Development" (SBD) research group at the University of Vaasa, and visiting professor at the University of South-Eastern Norway, as well as the Luleå University of Technology. Prof. Kohtamäki takes special interest in digital servitization, organizational change, strategic practices, and business intelligence.

Risto Rajala is an Associate Professor of Service Engineering and Management at Aalto University, School of Science. His research focuses on the digitalization of operations and services, the transformation of technology-based business, and the management of complex product-service systems.

Citation: Talaoui, Y., Kohtamäki, M., and Rajala, R. 2020. Seeking 'strategy' in business intelligence literature: Theorizing BI as part of strategy research Technology Innovation Management Review, 10(9): 27-37. http://doi.org/10.22215/timreview/1387

(cc) BY

Keywords: Business intelligence (BI), literature review, strategy as practice, strategy content, strategy process, strategy realms, conceptualization, definition. 